\title{
3D Printing Cellulose Hydrogels Using LASER Induced Thermal Gelation
}

\author{
Tim Huber 1,2,*iD, Don Clucas ${ }^{3}$ (D), Mathieu Vilmay ${ }^{2,+}$, Birte Pupkes ${ }^{4}$, James Stuart 5 (iD, \\ Simone Dimartino $4, \ddagger$ (iD) and Conan Fee ${ }^{1,2}$
}

1 School of Product Design, University of Canterbury, Private Bag 4800, 8140 Christchurch, New Zealand; conan.fee@canterbury.ac.nz

2 Biomolecular Interaction Centre, University of Canterbury, Private Bag 4800, 8140 Christchurch,

New Zealand; mathieu.vilmay@yahoo.fr

3 Department of Mechanical Engineering, University of Canterbury, Private Bag 4800, 8140 Christchurch, New Zealand; don.clucas@canterbury.ac.nz

4 Department of Chemical and Process Engineering, University of Canterbury, Private Bag 4800, 8140 Christchurch, New Zealand; Birte.Pupkes@gmx.de (B.P.); simone.dimartino@ed.ac.uk (S.D.)

5 Department of Physics, University of Canterbury, Private Bag 4800, 8140 Christchurch, New Zealand; jss84@uclive.ac.nz

* Correspondence: tim.huber@canterbury.ac.nz; Tel.: +64-3-369-4124 (ext. 94124)

$\dagger$ Current address: Syft Technologies, 3 Craft Pl, Middleton, 8024 Christchurch, New Zealand

$\ddagger$ Current address: Institute for Bioengineering, School of Engineering, University of Edinburgh, EH9 3JL Edinburgh, UK

Received: 21 May 2018; Accepted: 29 June 2018; Published: 2 July 2018

\begin{abstract}
A 3D printer was developed for the 3D printing of cellulose hydrogels using open source software and simple 3D printer hardware. Using a temperature-based sol-gel transition of cellulose dissolved in aqueous solutions of sodium hydroxide $(\mathrm{NaOH})$ and urea, a three-dimensional gel can be created by moving a focused laser beam across a bath of the cellulose solution and lowering the print stage after every layer. A line width of 100-150 $\mu \mathrm{m}$ and layer thickness of $25 \mu \mathrm{m}$ of the printed part could be achieved. No delamination between printed layers occurred and no additional support material was needed to create free hanging structures due to suspending the printed part in printing liquid. By adding cellulose powder to the solution, the gelation temperature, the gel strength and stiffness can be manipulated while maintaining a high internal porosity of the gel. A laser power of $100 \mathrm{~mW}$ was found to produce the highest quality print with an accurate representation of the previously designed part. Lower power settings $(80 \mathrm{~mW})$ produced insufficient gelation and as a result reduced print accuracy while higher power settings $(120 \mathrm{~mW})$ caused the gel to burn.
\end{abstract}

Keywords: 3D printing; cellulose; hydrogel; laser

\section{Introduction}

Three-dimensional networks of hydrophilic polymers with the ability to absorb and hold large amounts of water, or water-based liquids, known as hydrogels, are found in an extremely versatile, and increasing range of applications [1-3]. Especially hydrogels made from bio-based polymers, such as polysaccharides and/or proteins have become an area of interest within the last decade in tissue engineering, drug release, micro-fluidics and bio-separation due to their biodegradability, biocompatibility and tissue-like consistency, combined with a high internal porosity and favourable surface chemistry [4-7].

Shaping of hydrogels into the required designs remains a challenge, but recently, rapid prototyping processes, especially 3D printing, have enabled the production of complex, three-dimensional structures, 
yet, with varying degrees of part precision and resolution. Several different 3D printing principles can be employed, but material selection is strongly limited and is either dependant on chemical modification for UV cross-linking, thermal manipulation for fused deposition modelling (FDM) or fusion of powdered materials using high energy lasers, called selective laser sintering (SLS) [8].

Cellulose is a promising material for bio-scaffolds due to its biocompatibility paired with a high biodurability [9]. Other applications relying on structured porous hydrogels, such as stationary phases for liquid chromatography [10-13], membranes or microfluid devices are other possible application ranges for highly structured cellulosic materials [14]. However, processability, and especially "printability" is strongly limited by the necessity of using an appropriate solvent to shape cellulose, as it is not melt-processable [15], and thus, the 3D printing of cellulose is mostly unexplored. To extend the application potential of cellulose hydrogels in analogy with other biopolymers, new methods need to be found that allow its 3D printing. Some successful attempts to create three-dimensional cellulose objects have been reported lately; a combined approach of 3D printing and electrospinning of cellulose acetate has been used to produce three-dimensional cell scaffolds $[16,17]$. Cellulose acetate was also 3D printed using a fused deposition modelling approach, depositing a solution of cellulose acetate in acetone in a layer-by-layer fashion until the designed object was completely formed. The cellulose acetate could then be converted into cellulose by immersion in ethanol [18]. Successful 3D prints have also been achieved using solutions of cellulose in $\mathrm{N}$-methylmorpholine-N-oxide (NMMO) printed on a commercially available bioplotter [19]. However, overall the 3D printing of cellulose has been strongly limited to the printing of either cellulose nanofribrils $[20,21]$ or cellulose derivatives such as carboxymethyl and hydroxyethyl cellulose [22-25].

Aqueous solutions of sodium hydroxide and urea are a low-cost solvent for cellulose when cooled to temperatures below $0{ }^{\circ} \mathrm{C}$ [26]. Such produced cellulose solutions can be gelled rapidly by increasing the solution temperature [27-29], making it an attractive system for 3D printing processes. While only a small amount of cellulose can be dissolved $(\sim 5 \%)$ the final gel can be strengthened by the addition of additional cellulose particles acting as a physical cross-linker or/and by the use of a chemical cross-linker, e.g., epichlorohydrin [27,30-32]. The solvent can be replaced by water in a simple washing process, resulting in a cellulose hydrogel.

It is known that laser, at a distinct wavelength of light, can transmit thermal energy. Using appropriate optics, the light can be focused to a spot size in the micron range. Thus, we will describe herein the use of thermal energy in the form of light as a mechanism to gel cellulose locally and continuously to create a three-dimensional structure for the first time. Despite the rapid rise of using 3D printing for a growing range of (high-tech) applications, the development of specific 3D printing technology is less common, with some exceptions like the printing of tissue scaffolds or the 3D printing of food products $[33,34]$. This can at least be partially explained by the very high cost of specialised or high-quality printers in combination with severe material restrictions of lower cost open-source systems [33-35]. Thus, next to an analysis of the selected materials and resulting prints we will demonstrate how a material and application specific 3D printer can be designed and developed for significantly less than US $\$ 10,000$ using open source software.

\section{Materials and Methods}

\subsection{Chemicals}

Sigmacell Cellulose powder, Type 20 (average particle diameter $20 \mu \mathrm{m}$ ), and Urea (ACS grade) were purchased from Sigma-Aldrich (Sigma-Aldrich, St. Louis, MO, USA). Sodium Hydroxide (purity 97\%) was purchased in pellet form from Thermo Fisher Scientific (Waltham, MA, USA). All chemicals were used as-received. 


\subsection{Laser Optics}

The used laser diode was collimated and passed through an expanding lens with a focal length of $25 \mathrm{~mm}$. A Newport Power Meter 1918-R (Newport, Irvine, CA, USA) and manual iris (ThorLabs Stainless Steel, Post-Mounted Iris Diaphragm ID25SS, (Thorlabs Inc., Newton, MA, USA) were positioned in the path of the beam where the entire beam was expanded to be $25-30 \mathrm{~mm}$ wide. By setting the iris to be approximately $1 \mathrm{~mm}$ in diameter the laser beams spatial profile could be found using a Melles Griot Linear Translation Stage (Melles Griot, Rochester, NY, USA). The spatial filter (model KT310/M) was purchased from ThorLabs, with a $25 \mathrm{~mm}$ focusing lens, $100 \mu \mathrm{m}$ pin hole and a $50 \mathrm{~mm}$ lens for collimation. Power measurements of the used Laser diode were conducted using a PM100USB Thorlabs power meter with an attached S401C sensor (Thorlabs Inc., Newton, MA, USA). A Powertech MP-3086 DC power supply (TechBrands by Electus Distribution Pty. Ltd. Rydalmere NSW, Australia) was used. The power output of the laser diode was controlled by adjusting the current through the power supply. The power output was calibrated by adjusting the current in $0.5 \mathrm{~mA}$ steps and measuring the power of the laser diode using the Thorlabs power meter and sensor. A complete list of all used components can be found in the supplementary bill of materials.

\subsection{Printer Design and Construction}

The laser optics were attached to an $x-y$ stage sitting above the building platform. The $x-y$ stage was guided with 3 linear bearings on 2 linear shafts of $8 \mathrm{~mm}$ on each axis. Two stepper motors (NEMA 17) were used to control the $X$ and $Y$ axis movement. The stepper motor movement was translated into linear movement using two M8 $\times 1.25 \mathrm{~mm}$ threated rods. The maximum speed to allow smooth movement along the $x$ - and $y$-axis was determined to be $3 \mathrm{~mm} / \mathrm{s}$ and was used for all performed prints. All motors, belts and rods as well as the used electronics were purchased from MAKERshop (Auckland, New Zealand).

A micrometer (MATRIX, $1 \mathrm{div}=0.002 \mathrm{~mm}, 1 \mathrm{rev}=0.5 \mathrm{~mm}$ ) driven by a belt (timing belt GT2 $6 \mathrm{~mm}$, black neoprene rubber) was used to control the print height and achieve a high precision in $z$-direction of approximately $2 \mu \mathrm{m}$. This micrometer was attached to a stainless-steel piston of $20 \mathrm{~mm}$ diameter, guided in a precision-machined aluminum piece. The two parts were lubricated with silicon oil to achieve translation without any friction forces. A stage, with a diameter of $20 \mathrm{~mm}$ made from ABS, was mounted on top of this piston to hold the printed part. The ABS stage held a layer of $1 \mathrm{~mm}$ thickness of cellulose gel used as a built plate for the printed part.

The part was build layer-by-layer, where individual layers were created by the $x-y$ movement of the focused laser beam and subsequent gelling of solution, followed by a lowering of the build plate by a defined layer thickness in $z$-direction. For each layer, cellulose solution was wiped across the built plate using a custom designed and printed (Connex Object 500, Stratasys, Ltd, Eden Prairie, MN, USA) wiping arm holding a razor blade at a $45^{\circ}$ angle. 2 servomotors (HOBBY YM2765) were used to drive the arm. The solution was continuously supplied using a syringe pump set to a feed rate of $8.5 \mathrm{~mL} / \mathrm{h}$. After each wiping step, excess solution was removed using an attached vacuum pump. A 3D model of the model is supplied in the Supplementary Material online.

All mechanical parts were controlled through an Arduino Mega2560 including a RepRap Arduino Mega Pololu Shield. CAD was used to generate the parts in stl file format, using Solidworks 2015 (Dassault Systèmes, Vélizy-Villacoublay, France). The files were sliced into individual layers of a chosen layer thickness using Slic3r (Alessandro Ranellucci, GNU GPL, http: / /www.slic3r.org), simultaneously creating the G-code controlling the movement along all three axes. A G-code sequence to control the movement of the wiping system was added manually to Slic3r. A detailed list of all used hardware and software, as well as a CAD model of the designed printer and photographs of the designed model can be found in Appendix A.

The printer and syringe pump were placed in a refrigerator at $1-3{ }^{\circ} \mathrm{C}$ during the printing process to avoid an unwanted gelation of the used cellulose solution. 


\subsection{Preparation of the Cellulose Solutions and Gels}

A solution of $12 \mathrm{wt} . \%$ urea and $7 \mathrm{wt} . \% \mathrm{NaOH}$ in MiliQ water was prepared and cooled down to $4{ }^{\circ} \mathrm{C}$. $5 \mathrm{wt}$.\% of Sigmacell cellulose powder was added to the solution and stirred vigorously using a Silverson overhead mixer (Silverson Machines, Inc., Longmeadow, MA, USA) at $5000 \mathrm{rpm}$ for approximately $3 \mathrm{~min}$, until all cellulose powder was dispersed and no powder agglomerates were visible. The suspension was stored at $-12{ }^{\circ} \mathrm{C}$ for $4-6 \mathrm{~h}$ until a clear solution had formed and was then stored at $1-2{ }^{\circ} \mathrm{C}$ until further use. The final cellulose concentration was found to be $4.99 \pm 0.2 \mathrm{wt} . \%$ (formulation 1).

To modify the solution viscosity and strengthen the resulting gel, $50 \mathrm{wt} . \%$ of the initially dissolved cellulose portion was added in the form of more Sigmacell powder and stirred into the solution using the overhead mixer at approximately $800 \mathrm{rpm}$. The solution was stirred for approximately 5 minutes until the added powder was evenly dispersed in the original solution and no agglomerates were visible (formulation 2).

Bulk samples for mechanical and optical analysis were prepared by pouring the solution (formulation 1) and the solution mixed with additional cellulose powder (formulation 2) into rectangular moulds $\left(50 \times 50 \times 30 \mathrm{~mm}\right.$ ). The moulds were placed in an oven at $70{ }^{\circ} \mathrm{C}$ for $30 \mathrm{~min}$ to gel the solution. The gel was then placed in a distilled water bath for approximately $72 \mathrm{~h}$ to completely remove the solvent. The water was exchanged every $24 \mathrm{~h}$.

Only formulation 2 was used to conduct 3D printing. For 3D printing the solution, the cellulose powder was dispersed in the above described manner (formulation 2) in the presence of $0.1 \mathrm{wt} . \%$ of water-based green food colouring (Hansells Food Group, Auckland, New Zealand) to improve energy adsorption of the solution from the blue laser diode. The solution mixture was stored at $1-2{ }^{\circ} \mathrm{C}$ until loading into the syringe pump.

\subsection{Rheology}

The gelling behaviour and gelation temperature of formulation 1 and 2 was measured using a temperature ramp of $3{ }^{\circ} \mathrm{C} /$ min under constant low shear of $0.1 \mathrm{~s}^{-1}$ using an Anton Paar MCR 102 rheometer (Anton Paar, Graz, Austria) with a concentric cylinder and $50 \mathrm{~mL}$ cup. The starting temperature was $8{ }^{\circ} \mathrm{C}$ and the measurements were stopped at $95{ }^{\circ} \mathrm{C}$ to prevent boiling of the solution. Gel and curing point were determined using the Anton Paar software Rheoplus. The gel point was defined as the steepest point of the slope in viscosity increase.

\subsection{Mechanical Testing}

Samples were cut from the regenerated bulk hydrogels made from formulation 1 and 2 by using a circular sample cutter with a diameter of $25 \mathrm{~mm}$. Samples were kept in distilled water at room temperature prior to testing. Testing was carried out using an MTS Criterion Model 43 Universal Testing machine with crosshead control (MTS, Eden Prairie, MN, USA). Circular compression clamps with a $40 \mathrm{~mm}$ diameter were used. A $500 \mathrm{~N}$ load cell was used for all samples. The used crosshead speed was $1 \mathrm{~mm} / \mathrm{min}$. Before testing, each sample was removed from the water bath, excess water was wiped off using a paper towel and the sample was covered with a drop of low viscosity silicon oil to avoid frictional shear during testing. The samples were then placed between the compression clamps and a pre-load of $0.1 \mathrm{~N}$ was applied. Samples were tested to yield.

\subsection{Print Analysis}

To find a useable power setting of the laser diode that gels the solution but avoids burning it, simple rectangular strips $(1 \times 5 \times 0.2 \mathrm{~mm})$ were printed on sample holders of previously gelled cellulose. Three strips were printed on one sample holder each and adjusting the power between each strip. A low $(\sim 80 \mathrm{~mW})$, medium $(\sim 100 \mathrm{~mW})$ and high $(\sim 120 \mathrm{~mW})$ power setting were used to print the strips. Variations of $2-3 \mathrm{~mW}$ were observed for all power settings. 15 samples were 
printed. The samples were then washed with solvent to remove any residual ungelled solution and placed in deionised water to regenerated the cellulose. Samples were then stored in MilliQ water. For the analysis, samples were tapped dry before analysis using microfiber paper towel (Kim-Wipe, Kimberly-Clark, Irving, TX, USA) and photographs were taken of the sample surface using a Toupcam UCMOS01300KPA camera and ToupView software (Touptek, Hangzhou, China) attached to a Nikon SMZ-1B confocal microscope (Nikon, Tokyo, Japan). The width of the printed part was measured using ImageJ (Wayne Rasband, National Institutes of Health, Bethesda, MD, USA) taking 30-50 measurements for each sample.

More complex shapes were printed using a medium power setting to analyse the ability of the printer to print 90-degree angles, and to validate layer-to-layer adhesion and the printing of overhanging structures. Samples were printed, rinsed and regenerated as described above. Photographs were take using the same camera and microscope. Additionally, the samples were analysed using scanning electron microscopy.

\subsection{Field Emission Scanning Electron Microscopy}

Printed samples and samples of the bulk gels were surface dried using paper towels and then freeze dried using a Labconco freezone2.5 freeze drier (Labconco Corporation, Kansas City, MO, USA) for 24-32 h. After drying the samples were gold-coated for $90 \mathrm{~s}$ in three cycles at $25 \mathrm{~mA}$ using an Emitech K975X coater (Quorum Technologies Ltd, East Grinstead, UK).

Field emission scanning electron microscopy (FE-SEM) was performed with a JEOL 7000F FE-SEM (JEOL Ltd., Tokyo, Japan) with a probe current of $7 \mathrm{~mA}$ under an acceleration voltage of $5 \mathrm{kV}$.

To compare the pore size distribution of the used formulations (solution and solution with suspended cellulose particles) 20 images were recoded for each sample and the pore sizes were measured using ImageJ. 200-300 measurements were taken for each solution.

\subsection{Theoretical Considerations of Laser Based Gelling}

For a theoretical analysis of the gelling conditions, we assume the heat transfer due to thermal dissipation to be negligible [36]. The layer thickness of the print and cross-sectional area of the laser beam give the resulting gel volume:

$$
V_{G e l}=A_{B} \times t_{L}
$$

With $\mathrm{AB}$ being the cross-sectional area of the laser beam and $t_{L}$ being the layer thickness. The specific heat of the solution was assumed to be identical to water being,

$$
\mathrm{C}_{\text {pbeam }} \approx 4.18 \mathrm{~J} \cdot \mathrm{g}^{-1} \cdot \mathrm{K}^{-1}
$$

The density of the solution was calculated based on the fractions of its individual components, with $\rho_{\text {water }}=1 \mathrm{~g} \cdot \mathrm{cm}^{-3}, \rho_{\text {urea }}=1.32 \mathrm{~g} \cdot \mathrm{cm}^{-3}, \rho_{\mathrm{NaOH}}=2.13 \mathrm{~g} \cdot \mathrm{cm}^{-3}, \rho_{\text {cellulose }}=1.5 \mathrm{~g} \cdot \mathrm{cm}^{-3}$, resulting in the gel density $\left(\rho_{\text {gel }}\right)=\sum \frac{\rho_{\mathrm{i}}}{\text { concentration }_{\mathrm{i}}} \times \frac{1}{1.05}=1.14 \mathrm{~g} \cdot \mathrm{cm}^{-3}$.

Based on the conducted measurements the gelation temperature is approximated as $53{ }^{\circ} \mathrm{C}$ and the storage temperature of the solution as $3^{\circ} \mathrm{C}$ resulting in a necessary temperature increase of $\Delta \mathrm{T}=50 \mathrm{~K}$. Thus, the energy necessary to gel a defined volume of solution is given as:

$$
\mathrm{E}_{\text {gelling }}=\mathrm{m}_{\text {gel }} \times \mathrm{C}_{\mathrm{p}_{\text {gel }}} \times \Delta \mathrm{T}
$$

With the mass of the gel $\mathrm{m}_{\text {gel }}$ given as

$$
\mathrm{m}_{\mathrm{gel}}=A_{B} \times t_{L} \times \rho_{\mathrm{gel}}
$$

The amount of energy necessary to gel the solution can be derived from the observed power $\mathrm{P}_{\text {Laser }}$ setting that results in gelling in combination with the speed of the laser beam $v_{L}$ and its cross-sectional area. The time the laser spends at one spot $t_{S}$ can be assumed to be constant:

$$
\frac{A_{B}}{v_{L}}=t_{S}
$$


Therefore, the energy emitted by the laser to cause gelation in the observed ranges of power is

$$
\mathrm{E}_{\text {laser }}=\mathrm{P}_{\text {laser }} \times t_{s}
$$

The percentage of light being absorbed by the solution has to be taken into account. The transmission $\mathrm{T}$ can be found experimentally as a fraction of the light being transmitted through a sample over a distance $\mathrm{D}$ at a given, constant wavelength of the light. Attenuation of light through a medium follows an exponential decay dependant on distance travelled and the transmission coefficient of the material, this coefficient can be found by a simple algebraic manipulation,

$$
\begin{aligned}
& \mathrm{e}^{\mathrm{aD}}=5.5 \times 10^{-6} \\
& \mathrm{a}=\frac{\ln \left(5.5 \times 10^{-6}\right)}{D} .
\end{aligned}
$$

where $\mathrm{a}$ is the transmission coefficient and $\mathrm{D}$ is the distance travelled. The absorption $\mathrm{A}$ can be found by

$$
\mathrm{A}=1-\mathrm{T}
$$

This gives the fraction of laser energy absorbed by the solution as

$$
\mathrm{E}_{\text {absorped }}=E_{\text {Laser }} \times A \times V_{\text {Gel }}
$$

While not part of the original consideration, heat dissipation can be included by observing any widening of the gelled path and correcting for the considered cross-sectional area. For the sake of considering multiple options, the time it takes for heat to dissipate must also be considered. If heat dissipation is a relatively slow process, i.e., if it takes significantly longer than $t_{S}$ for the heat to spread, then a laser travelling in a straight line will travel and begin heating new gel before heat can dissipate to it. So, there will only be heat dissipation on the edges of the line the laser makes, this means that the total volume of solution will only increase linearly rather than in a circular pattern.

\section{Results}

\subsection{Gelation Temperature and Solution Viscosity}

All tested solutions clearly undergo a rapid sol gel transition as expressed by a 10-100-fold, rapid increase in shear viscosity (Figure 1). Adding cellulose increases the viscosity of the solution and lowers the gel point from $63{ }^{\circ} \mathrm{C}$ to $52{ }^{\circ} \mathrm{C}$. After gelling, a minor increase in viscosity can be observed.

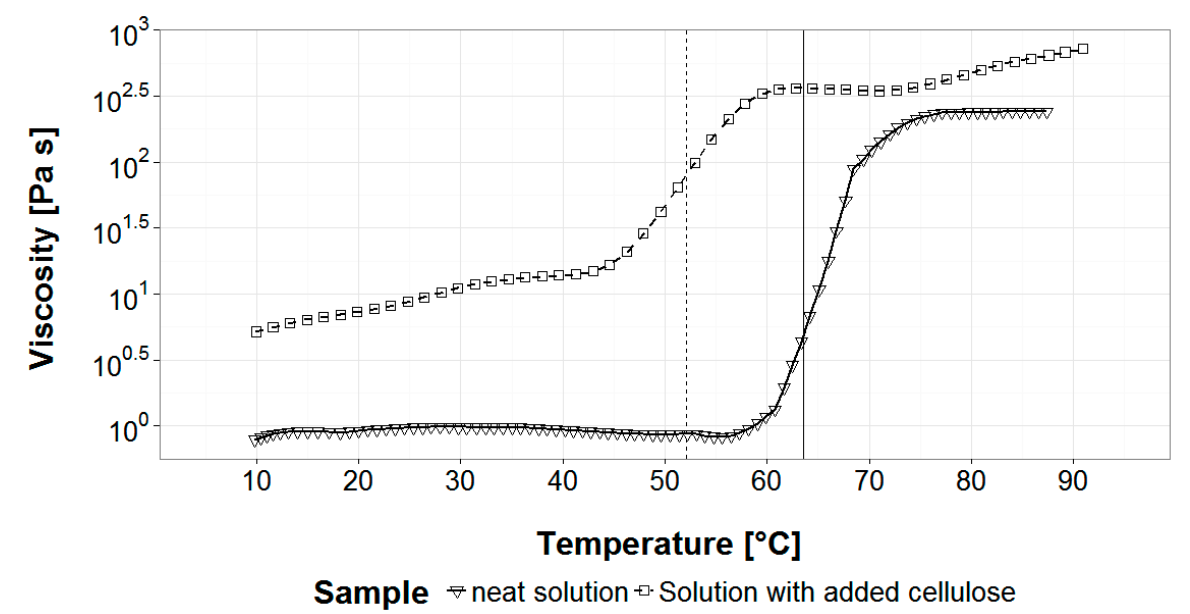

Figure 1. Shear viscosity of the tested cellulose solutions measured over a range of temperatures from $8{ }^{\circ} \mathrm{C}$ to $95^{\circ} \mathrm{C}$. The vertical lines mark the gel point of the solution determined as the steepest point of the slope. 


\subsection{Gel Microstructure and Mechanical Properties}

The microstructure of bulk samples of the gels produced from the neat solution (formulation 1), as well as the solution with added cellulose (formulation 2) were analysed using SEM (Figure 2). A vast network of open and closed pores can be seen in both samples, creating a large surface area. It is obvious that the addition of cellulose powder to the solution results in smaller pores.

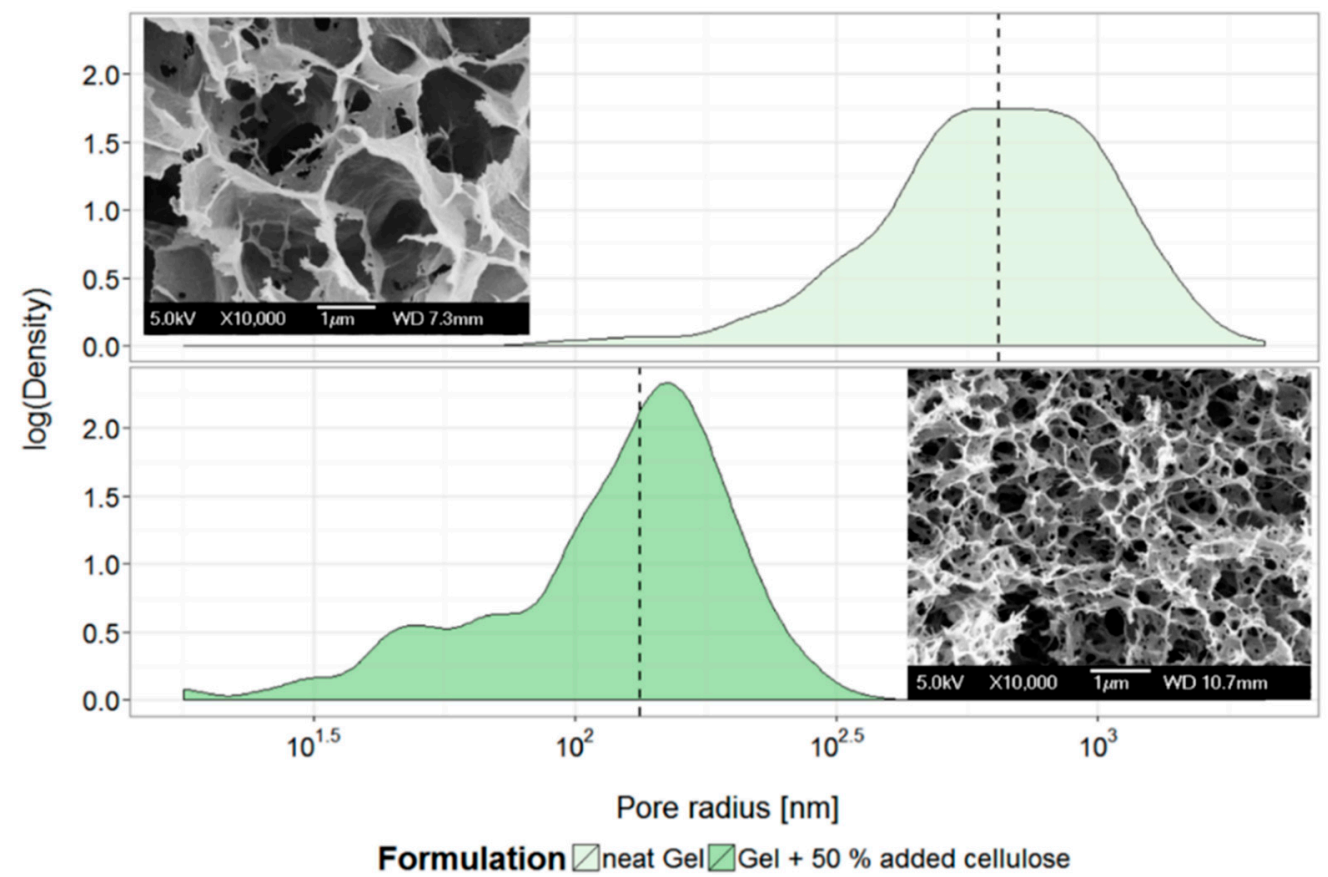

Figure 2. SEM micrographs and distribution of the measured internal pore radius of freeze-dried gel samples. Shown are the neat gel and the gel with $50 \%$ added cellulose powder. The lines represent the median value of the distribution. The addition of cellulose causes an almost 10 -fold reduction in internal pore radius.

The addition of cellulose could also be shown to have a strong effect on the mechanical properties of the produced gels. The added cellulose increase both, compressive modulus and strength by a factor of 2.3 (Figure 3).
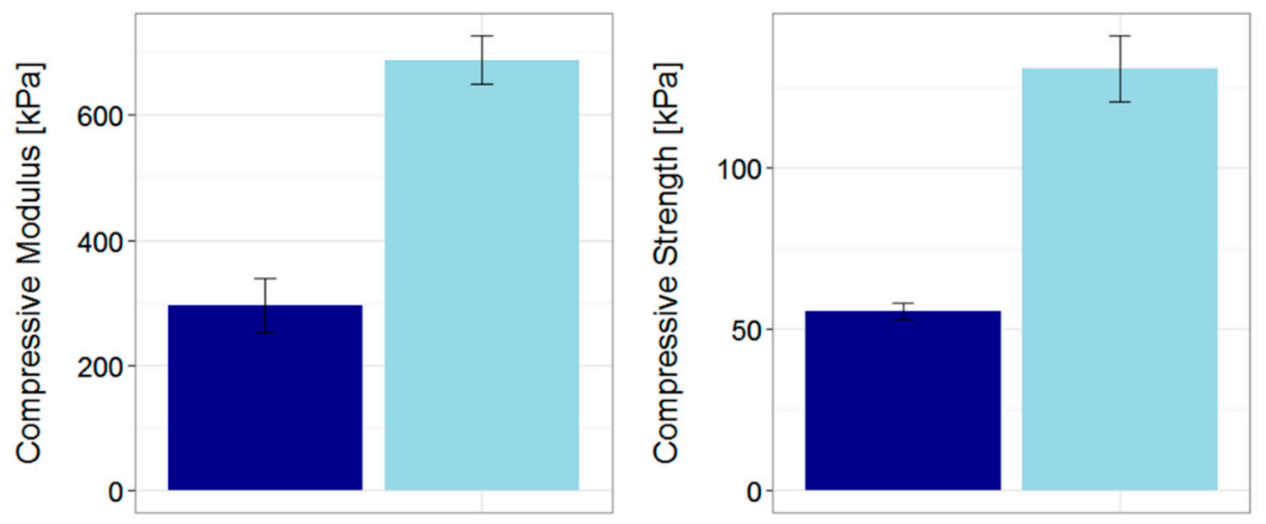

Added Cellulose [wt.\%] $\square 0 \square 0$

Figure 3. Measured compressive modulus and strength of bulk hydrogel samples. Shown are mean values of the neat gel and gel with added cellulose powder with one standard deviation. 


\subsection{Analysis of the Laser Spatial Profile and Filtering}

Various power outputs for the initial optical set-up were analysed and it was discovered that the spatial profile gets more distorted as power increases (Figure 4a). The spatial profile could be cleaned to an almost perfect Gaussian profile by directing the laser light of the diode through an additional spatial filter, but a dramatic loss of power was observed, resulting in a maximum measured power in the focal point of less than $20 \mathrm{~mW}$. Thus, the preferred method was to find a balance between beam profile and power loss. The filtered profile can be seen to be more Gaussian in shape than the unfiltered profile at the same power setting, and no large power spikes or dips are visible (Figure $4 \mathrm{~b}$ ).
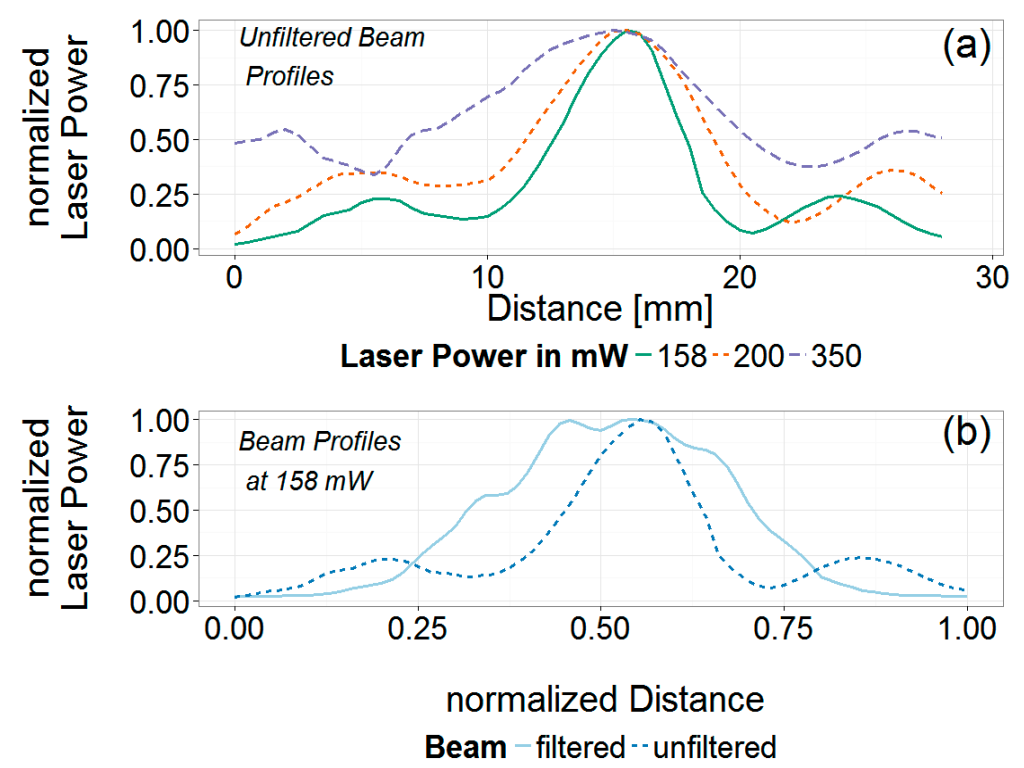

Figure 4. Unfiltered beam profiles of Diode 1 at different powers (a) and filtered and unfiltered beam at $158 \mathrm{~mW}(\mathbf{b})$.

The relationship between current input and power output from the laser diode is clearly linear all across the area of interest (Figure 5).

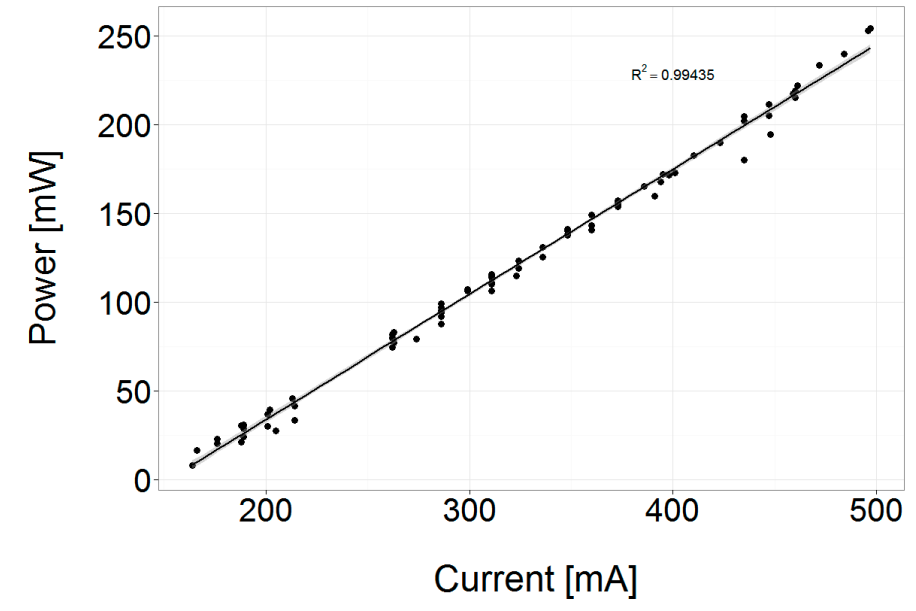

Figure 5. Calibration data of the used laser diode. A clearly linear relationship can be seen between set current and measured power output of the diode. A linear regression analysis was conducted using the statistical software $R$, and the $R^{2}$ value is displayed within the figure. The grey area marks the $95 \%$ confidence interval. 


\subsection{Print Analysis}

Small rectangular strips were printed to analyse the effect of the chosen power on print quality. All three chosen powers were sufficient to cause a gelation of the solution (Figure 6). The rectangular prints are well represented. However, at the lowest power setting, the printed shape is not showing straight edges and some banding can be seen in the printed part (Figure 6a). Additionally, the width of the part is below the designed $1 \mathrm{~mm}$. In contrast, using a medium and high power setting resulted in a more uniform print with straighter edges (Figure $6 b, c)$.
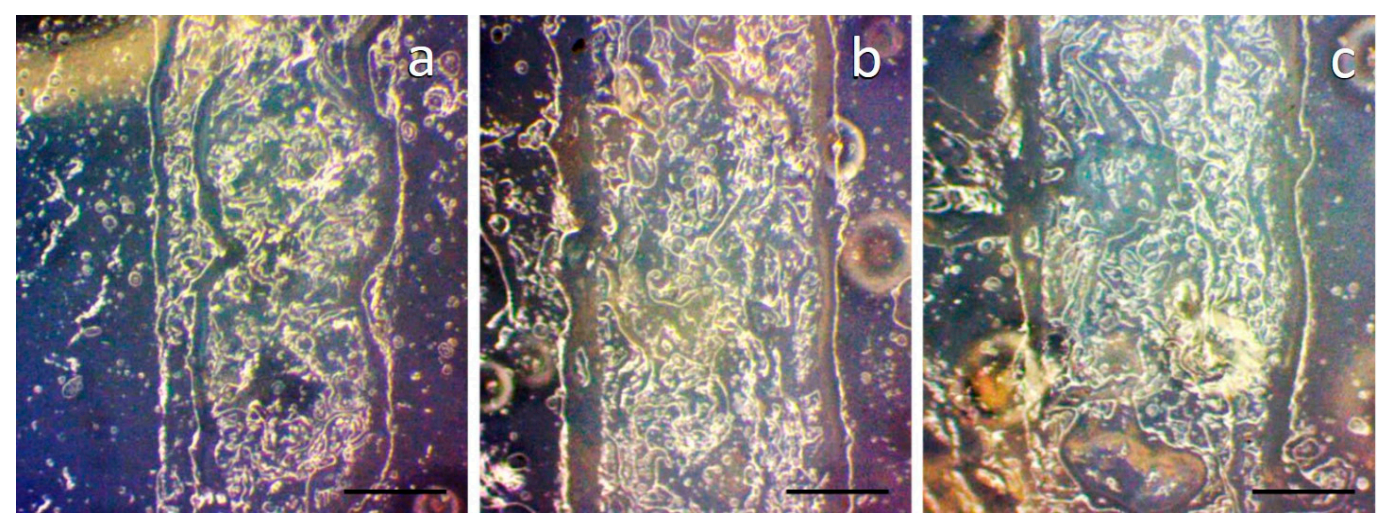

Figure 6. Optical photographs of a sample showing the printed, rectangular strips. The strips were printed, from left to right, using a low (a), medium (b) and high (c) power setting. The scale bar represents $500 \mu \mathrm{m}$ in all three images.

When using the higher power setting, spontaneous burning of the solution can occur, and the printed path maybe wider than designed as shown in Figure 7.

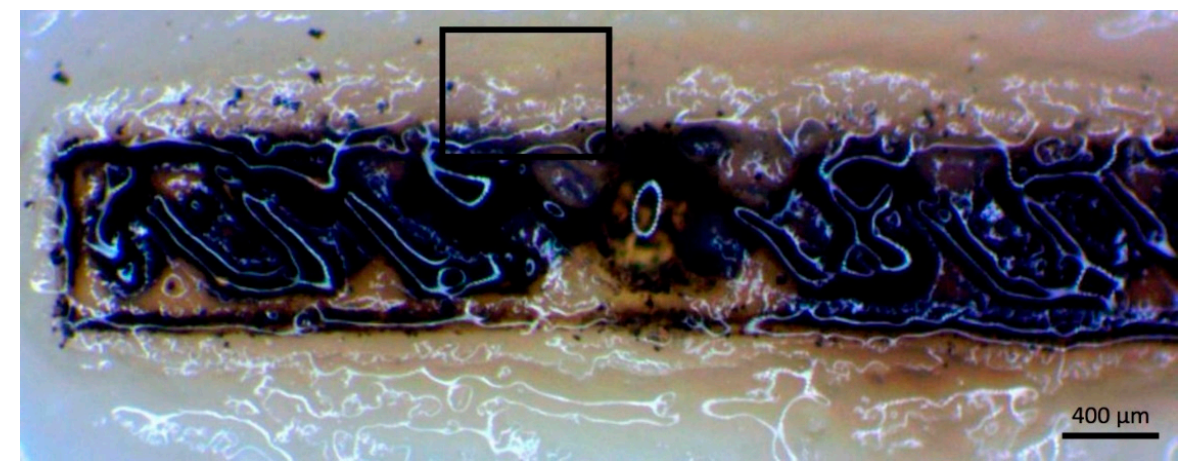

Figure 7. An image of a rectangular strip showing burn marks in the path of the gel. Excessive gelling can be seen near the burned material, as a result of excess heat being created.

To check the printing quality, the width of the printed part was measured, using optical images (Figure 8). Confirming the initial observations, the lowest power setting results in a printed path that is narrower than the designed $1 \mathrm{~mm}$ with a median of $909 \mu \mathrm{m}$ and an interquartile range (IQR) of $828-970 \mu \mathrm{m}$. Additionally, of the variations in measured values, $599 \mu \mathrm{m}$ is the highest of all three tested settings. On the other hand, the high-power setting results in a median part width of $1064 \mu \mathrm{m}$ and thus, is larger than the designed $1 \mathrm{~mm}$, as well it showed similarly high variation of $564 \mu \mathrm{m}$, as the low power setting. The IQR at the high-power setting $(161 \mu \mathrm{m})$ is also the highest of all three settings, compared to the low $(143 \mu \mathrm{m})$ and medium power setting $(93 \mu \mathrm{m})$. At the medium power setting, the parts show a very close match to the designed width with a median of $989 \mu \mathrm{m}$, and also a strongly reduced variation of $345 \mu \mathrm{m}$. 


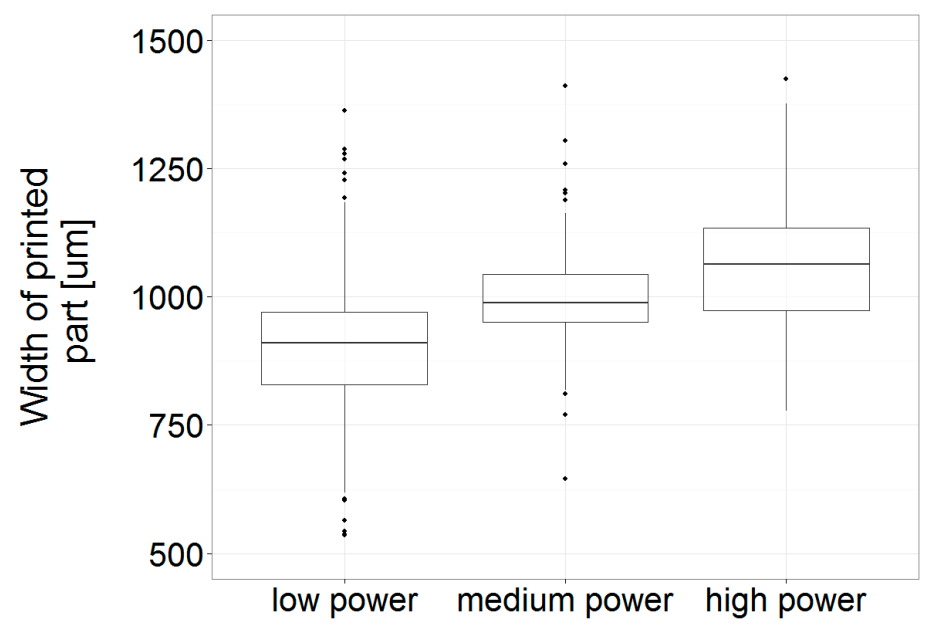

Figure 8. Distributions of the measured values of the width of the printed rectangular strips, printed at different power settings.

Using a medium power setting, printing multi-layered, three-dimensional parts with different geometries was trialled, all with a wall thickness of $1 \mathrm{~mm}$. Square and round shapes were printed, trying to achieve a part height of $1 \mathrm{~mm}$ with a layer thickness of $25 \mu \mathrm{m}$. Next to simply layered structures, it was also attempted to print a part with an overhanging structure without using additional support material (Figure 9). Both, the circle with an overall diameter of $10 \mathrm{~mm}$ and square with a side length of $10 \mathrm{~mm}$, show good layer adhesion and are a good representation of the designed part. In both parts there is a thin line of burned material visible on top of the print, but it does not appear in the walls of the parts. Printing an overhang without any additional support material was also possible.

Drawings with full dimensions of the designed parts are available in Appendix A.

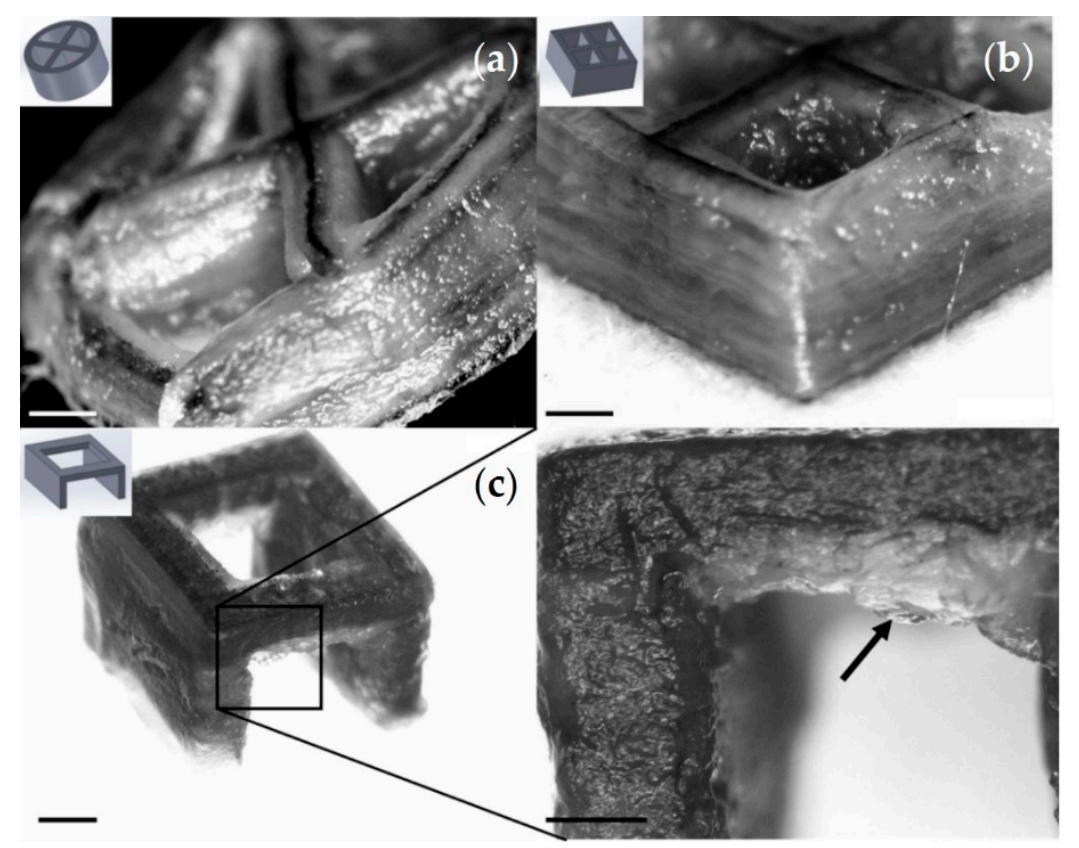

Figure 9. Optical photographs of 3D printed parts, showing a circular (a) and square shape (b), as well as a part with an overhanging beam printed without additional support material (c). The close up shows the overhanging part with some additional gelling occurring. The scale equals $1 \mathrm{~mm}$ in all images. The insets show CAD models of the designed parts. 
Samples of the simple geometries have been freeze-dried and analysed using SEM (Figure 10). The path taken by the laser is clearly visible in gelled and dried samples, with the path width being approximately $50 \mu \mathrm{m}$ (Figure 10a). The gaps are nonetheless filled with solid gel due to heat being distributed through the solution during gelation through the laser light. The magnified area shows the intersection of the laser path and fraction of material gelled through residual heat. Both areas show the typical porous structure observed for the bulk samples. Yet, small differences are apparent in that the directly irradiated area shows smaller pores than the area gelled by thermal dissipation. Figure $10 \mathrm{~b}$ shows a cross-section of a print and the individual layers are clearly visible. The layers' thickness appears to be constant at 25 microns with only small variations.
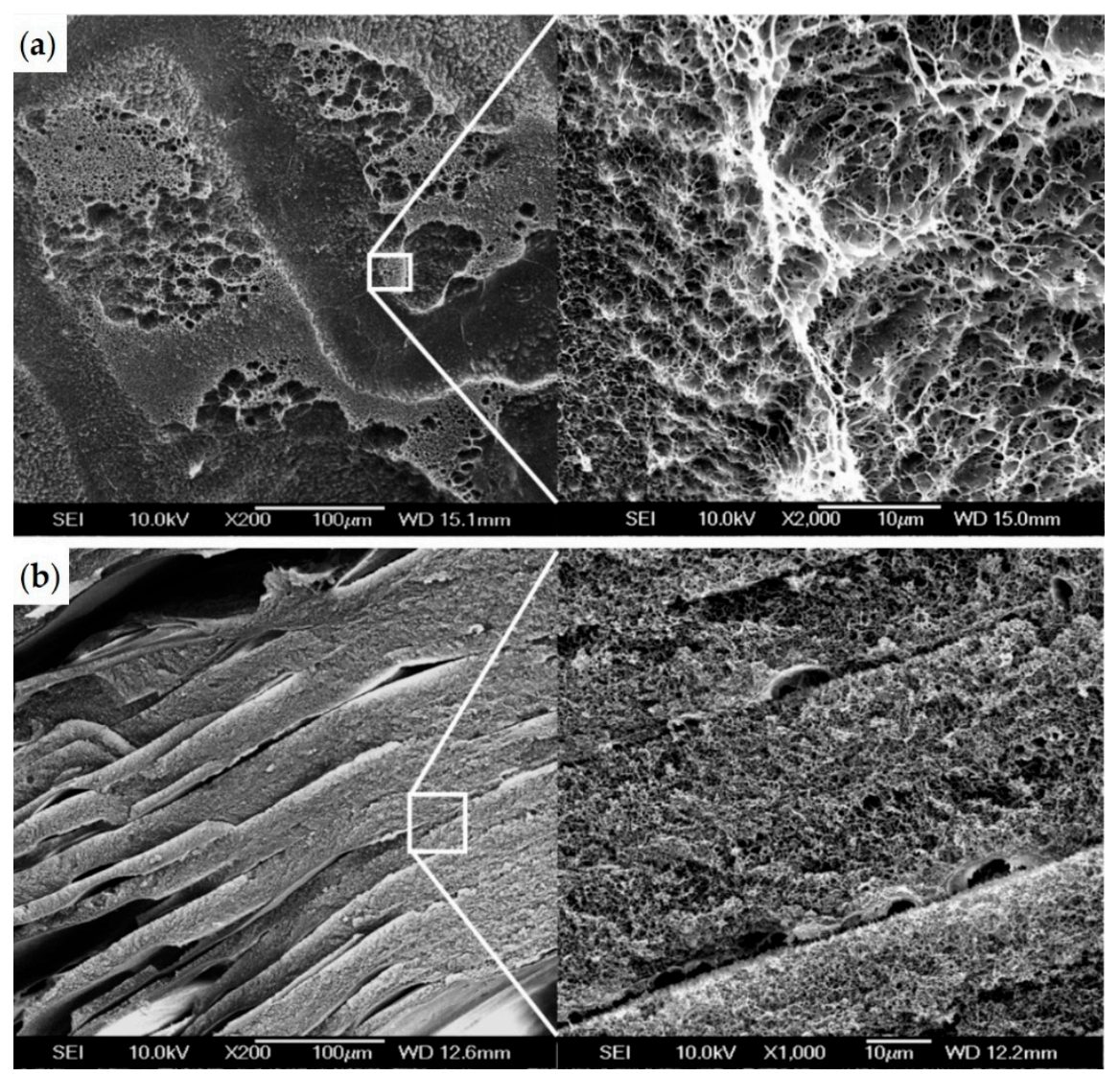

Figure 10. SEM micrographs of the 3D-printed parts. Shown, each with a close-up, are the path taken by the laser and the resulting gelled material (a) and a cross-section showing individually put down layers of gelled material (b).

\section{Discussion}

We believe the increased viscosity of the solution and lowering of the gel point in formulation 2 to be the result of a strongly increased number of hydrogen bonds between cellulose in solution and suspended cellulose particles, leading to the observed 10-fold increase in viscosity of the solution. The gelation is the result of a breakdown of a so-called inclusion complex surrounding individual cellulose chains [37]. The inclusion complex prevents the chains in solution form forming a permanent network and upon breakdown, this strong network forms very rapidly, as illustrated by the dramatic and rapid increase in viscosity at the gel point for both the original solution and solution with added cellulose [38]. After gelling, the solution starts to dry out leading to the observed minor viscosity increase. A further modification of gelling behavior and solution viscosity could be achieved by replacing the used urea with thiourea or poly-ethylene glycol, which could lead to improved stability of the solution [39-41]. 
The additional cellulose powder in formulation 2 acts as a physical cross-linker due to vastly increased bonding sites for the formation of hydrogen bonds, not only leading to an increased viscosity, but also leads to a denser network of cellulose chains and thus smaller internal pore sizes $[42,43]$. The cellulose powder acts as both, a physical cross-linker leading to the reduced pore diameter as well as a reinforcing agent. Using cellulose as a matrix material as well as a reinforcing phase, in so-called all-cellulose composites, show good adhesion between the two phases, due to chemical similarity [44]. The same effect can be observed for the tested hydrogel, resulting in the strongly increased strength and stiffness, placing the hydrogels produced here in the same range of mechanical properties as, for example, calcium alginate or chitosan, both commonly used in tissue engineering [45,46].

As the laser power increases the spatial profiles gets less Gaussian, most likely due to new modes switching on, as shown by smaller peaks in the profile (Figure 4a). The height and width of those smaller peaks increase with increasing laser power, meaning that with higher power settings the unfiltered beam could create a triple beam profile within the gelled solution, resulting in poor representation of the designed path in the gel. The additional modes can cause additional, undesired gelling, and therefore need to be filtered out. The linear relationship between current input and power output allows for direct and accurate control of the heat necessary for gelation of the cellulose solution.

The effect of laser power on the printed part is clearly visible in the printed test pieces. Reduced power results in lower spot heat and thus, less gelation of the cellulose solution. Although the solution does undergo a sol-gel transition in the focal point, the residual heat is causing little or no spreading of the gelation. Banding that was seen in some samples can be explained by the underlying hexagonal fill pattern employed by the Slicr software and the translation of the linear movement by the rotation of the stepper motors. Spontaneous burning that occurs at higher power settings is possibly due to larger cellulose particles being coloured unevenly by the food dye, or inconsistent movement of the stepper motors leading to a slightly increased heating time for a single spot (Figure 7). A single burnt spot will cause successive burning, as the charred and thus black surface will absorb additional energy. The additional energy in turn leads to more gelling in the periphery of the focal point causing the printed path to be wider than designed. This behaviour confirms our previous assumptions of a linear heat dissipation, resulting in a wider gelled path with higher power. A similar phenomenon can also be observed in SLS, where the width of the sintered part becomes less predictable at higher laser powers and/or lower speed of movement $[35,36]$. The high variation in measured width of the printed part for the lowest power setting means that although gelling does occur, the applied power is not high enough to result in a good representation of the designed part. The medium power setting, it the best option out if the three tested with the least amount of variation in path width and without any burned parts. However, the ideal power setting will strongly depend on the used printing speed and printed object. Thus, no general recommendations for the ideal setting can be given. Overall, the chosen designs were much more accurately represented in the printing than for example, in laser sintered scaffolds made polyamide or polycaprolactone $[47,48]$.

The laser path is determined by the slicing software, and as result of the part design, it moved along the middle line twice, possible leading to overheating and burning. While the solution and part are cooled during the printing process, ageing of the present solution does take place during the printing, which can cause a higher sensitivity of the solution towards heat, and this could explain why the burning only appears in the topmost layers. Better temperature control, a better optimised algorithm for creating the layer movement, or a small reduction of the laser power over the printing time are likely solutions to avoid those problems.

While the solution undergoes a change from liquid-like to gel-like upon heating, no other physical changes occur. This in turn means the gel is suspended in a liquid of equal density, and as a result, the gravity acting on the part will not cause any deformation, making the use of any support material obsolete and allowing the printing of overhangs even at the shown 90 degrees, analogous to the cellulose nanocrystal gels produced by $\mathrm{Li}$ et al. [49] from non-derivatized cellulosic material. 
Additionally, the printed samples show that the cellulose gel is strong enough to support itself once removed from the solvent and regenerated, as also observed for cellulose gels made through the exposure of an ionic liquid solution of cellulose to methanol vapour [50]. Thus, thin layers of gel formed through residual heat of the first overhanging, could be caused by the solution being warmer at this stage of the print and as a result, the application of the same amount of power causes excess gelling. The printed parts needed no further cross-linking while achieving similar print fidelities as 3D printed hydrogels made from a mixture of cellulose nanocrystals and gelatin/alginate as reported by Sultan and Mathew [51] or Leppiniemi et al. [52].

SEM analysis of the printed parts show the typical porous structure observed for the bulk samples in the samples printed using laser gelling, which was not visible in the parts printed using the bioplotter or cellulose acetate $[18,19]$. It is possible that the speed of heating influences the sol-gel transition of the solution and as a result impacts on the pore formation, explaining the small differences in microstructure between the directly irradiated area and the area gelled by thermal dissipation. However, the gelling behaviour of the used cellulose solution has not been explored in detail and no conclusions should be drawn without further testing.

\section{Conclusions}

The designed prototype was successful at printing small parts made entirely from cellulose by gelling the cellulose through laser induced heating. The printed parts show good layer-to-layer adhesion as well as the desired highly porous internal structure necessary to create the large surface area desired in many applications. The gel point, microstructure and mechanical properties of the gel can be easily adjusted by the addition of cellulose powder acting as a physical cross-linker and reinforcing phase. The applied power needs to be adequately controlled to achieve prints of the desired high resolution.

Supplementary Materials: The following are available online at http:/ /www.mdpi.com/2504-4494/2/3/42/s1, Figure S1: Model of the 3D printer.

Author Contributions: T.H., S.D. and C.F. conceived and designed the experiments. M.V. designed the apparatus and carried out all 3D printing work. D.C. contributed strongly to the design of the apparatus and supported the experimental design. J.S. designed and installed the laser optics and contributed to writing of Section 3.1. B.P. contributed to the experimental work and analysis. T.H. wrote the paper and conducted most of the analysis with input and feedback from S.D., C.F., D.C. and M.V.

Acknowledgments: The authors would like to acknowledge the funding for this research provided by the New Zealand Ministry for Business, Innovation and Employment under the MBIE Smart Ideas funding scheme (UOCX1304). The authors are very grateful for the advice and helpful comments of Professor Roger Reeves. The authors would like to thank Mike Flaws and Rayleen Fredericks for technical assistance.

Conflicts of Interest: The authors declare no conflict of interest.

\section{Appendix A}

\section{COMPONENTRY}

\section{- Arduino Mega2560 + RepRap Arduino Mega Pololu Shield, (RAMPS 1.4) Control boards}

- The Funduino Mega2560 is a clone of the Arduino Mega 2560. It features an Atmel ATmega2560 processor. It has 54 digital input/output pins and 16 analog input pins. 14 of the output pins can be used as pulse width modulated (PWM) outputs.

- The R3 features a couple of improvements over the original 2560 and R2. The reset circuit has been improved and the USB communications is done with a $16 \mathrm{U} 2$ chip instead of the $8 \mathrm{U} 2$. There are also a few extra pins available.

- Sockets for up to 5 Pololu style stepper drive modules. $X, Y$, and $Z$ axes and 2 extruders.

- 3 channels of temperature sensing using $100 \mathrm{k}$ thermistors (not included) for heated bed, and 2 extruders. 
3 channels of MOSFET switched output for controlling extruder heating, hot bed heating and cooling fan speed. Includes Heat sink for the heated bed MOSFET.

- NEMA 17 Stepper motors $580 z-i n$ 0.9\% $/$ step:

2-phase with 4-wire bipolar windings.

Shaft Diameter: $5 \mathrm{~mm}$ without flat face

Step Angle: $0.9^{\circ}$ (400 step/rev)

Motor Length: $48 \mathrm{~mm}$

Rated Current: 1.7 Amps per phase

Phase Resistance: $1.65 \mathrm{ohms}$

Phase Inductance: $4 \mathrm{mH}$

Holding Torque: $58 \mathrm{oz}-\mathrm{in} / 41 \mathrm{~N} \cdot \mathrm{cm} / 4.2 \mathrm{~kg} \cdot \mathrm{cm}$

Detent Torque: $220 \mathrm{~g} \cdot \mathrm{cm}$

Rotor Inertia: $68 \mathrm{~g} \cdot \mathrm{cm}^{2}$

Weight: $358 \mathrm{~g}$

- Stepper motor drivers: A4988 Pololu

- Servo Motor: Standard $6 \mathrm{~V}$ with Metal Gear-11 kg, for the wiper.

- Limit switch: Roller level miniature microswitch

- Thermistor: Thermistor EPCOS B57560G104F

- Connectors: Jumper 2, 3 and 4 pins Dupont $70 \mathrm{~cm}$

- Power supply: Benchtop power supply 16 A 13.5 V VDC

- $\quad$ Regulated power supply: Powertech DC regulated power supply-MP3086

- Mechanical parts

- Linear shafts: Linear shaft $8 \mathrm{~mm}$

- Linear bearing: Linear bearing Bush LM8UU

- Shaft support: SK8 shaft support for $8 \mathrm{~mm}$ shaft

- Coupling: Flex coupling 5-8 mm

- Pulley: Pulley GT2 16, 20 tooth

- Belt: Timing belt GT2 $6 \mathrm{~mm}$ black neoprene rubber

- Threated rod: M8 threated rod stainless steel (304)

- Openbeam: Profile $40 \times 40$ SlotPro Standard Extrusion, Autoline 1.0404.4.SPSS

- Laser

Laser diode: Roithner Laser diode $450 \mathrm{~nm}, 1.6 \mathrm{~W}$, ref: LD-450-1600MG Cage System

- Vertical cage mount

- $\quad$ Cage rods: $152.4 \mathrm{~mm}, 101.6 \mathrm{~mm}, 76.2 \mathrm{~mm}$

- $\quad 30 \mathrm{~mm}$ Cage plate

Pinhole, $100 \mu \mathrm{m}$ :

- Bi-convex $50 \mathrm{~mm}$ lens:

- Bi-convex $25.4 \mathrm{~mm}$ lens:

- Bi-convex $75 \mathrm{~mm}$ lens

- Bi-convex $150 \mathrm{~mm}$ lens

- Threaded cage plate

- Z-axisTranslation Mount, $30 \mathrm{~mm}$ Cage compatible 
Wiring

We used a $12 \mathrm{~V}$ relay to command the laser diode through the RAMPS D9 output. The 2 wires coming from the RAMPS are plugged on the relay command. The signal coming from the D9 output commands (switch ON and OFF) the contact of the relay. This contact is plugged to the negative wire $(-)$ from the Power supply. The Positive wire (+) form the power supply is plugged to a multimeter to measure the laser diode current.

- Servo motors wiring

The servo motors are powered by an external $6 \mathrm{~V}$ power supply and controlled by plugging their signal wire onto the RAMPS (see the servo motor P0 \& P1 on the RAMPS).

P0 Servo motor controls the horizontal moves of the wiper and the P1 servo motor controls the lift of the wiper.

Figure A1 shows the CAD model of the printer design. Figure A2 shows photographs of the built model.

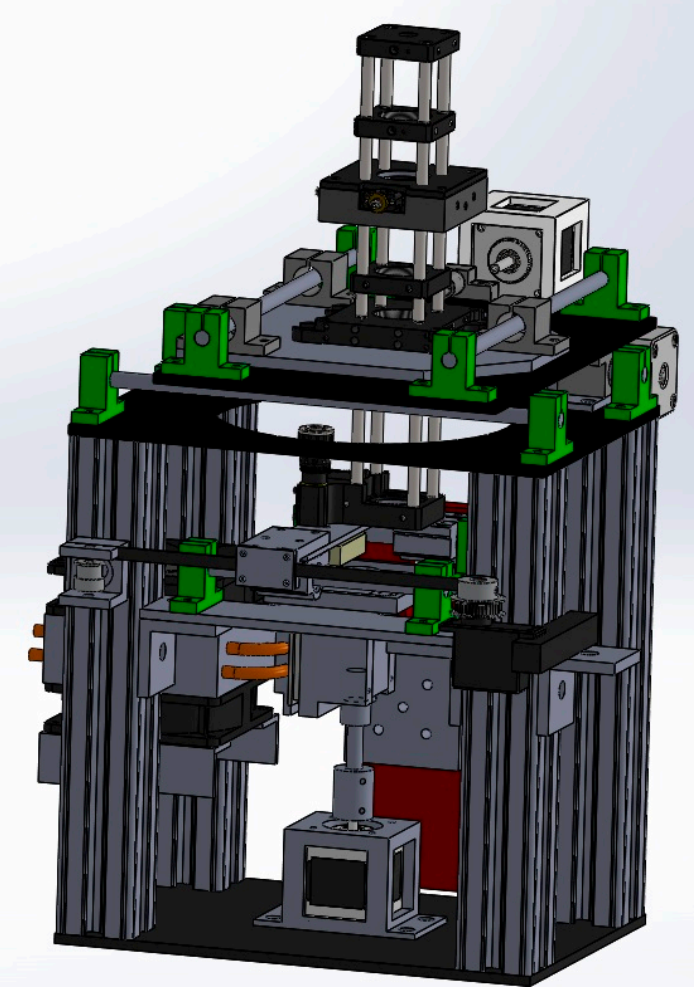

Figure A1. CAD model of the fully designed printer set-up, created with in Solidworks. 

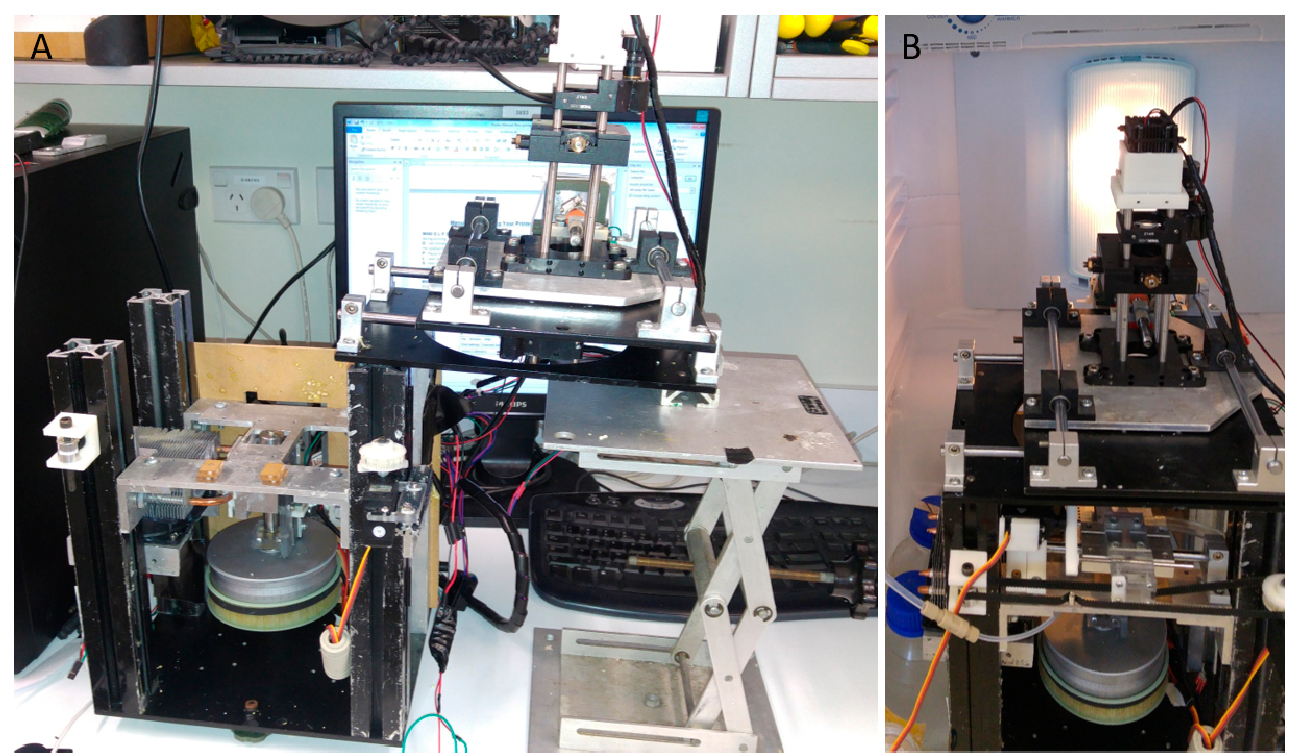

Figure A2. Photographs of the built printer model, disassembled in-between prints (A), and during a print while placed in a refrigerator $(\mathbf{B})$.

\section{Sofware}

\section{- $\quad$ Repetier-Host Windows 2.0.5}

- Marlin G-Code: Marlin Firmware runs on the 3D printer's main board, managing all the real-time activities of the machine. It coordinates the heaters, steppers, sensors, lights, LCD display, buttons, and everything else involved in the 3D printing process.

- $\quad$ Slicing Slicer prepares a solid 3D model by dividing it up into thin slices (layers). In the process, it generates the G-code that tells the printer in minute detail how to reproduce the model.

\section{CAD Models for Printing}

Figure A3 shows the dimensions of the 3 different designs used to test the printer.
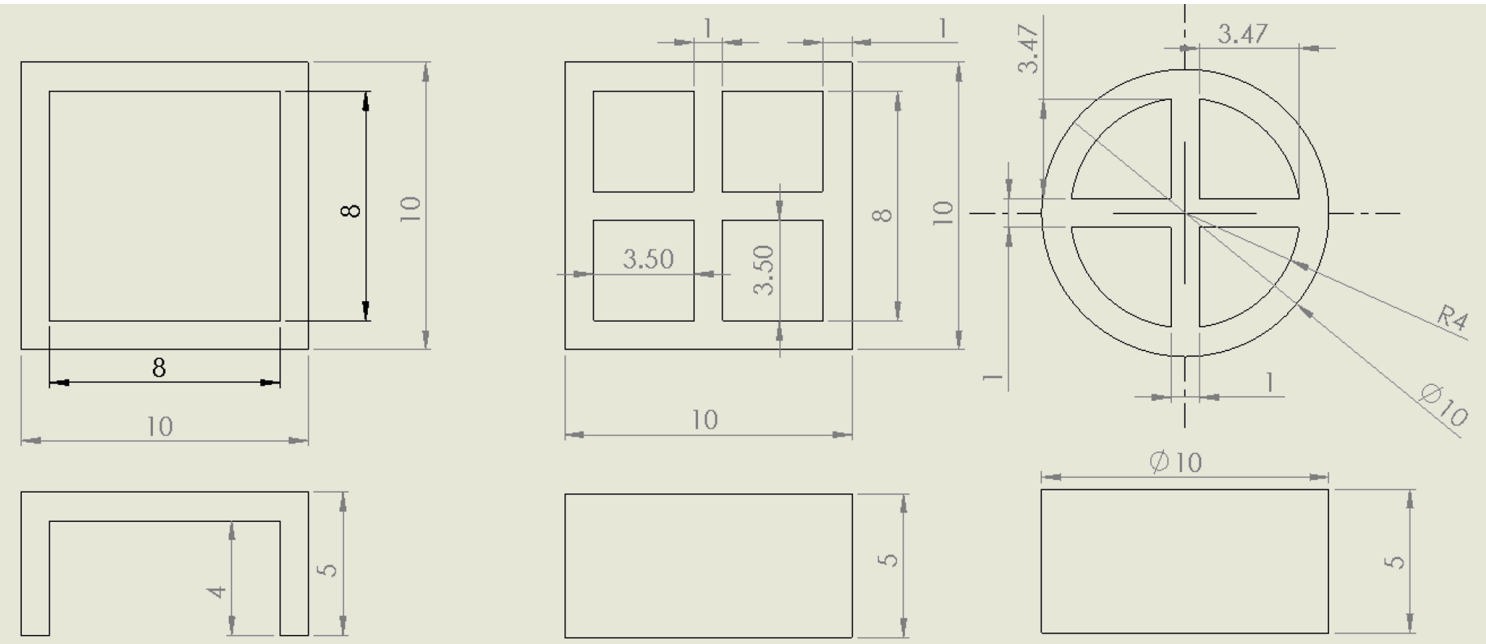

Figure A3. Dimensions of the designed geometries used to test the printer. 


\section{References}

1. Sannino, A.; Demitri, C.; Madaghiele, M. Biodegradable cellulose-based hydrogels: Design and applications. Materials 2009, 2, 353-373. [CrossRef]

2. Shen, X.; Shamshina, J.L.; Berton, P.; Gurau, G.; Rogers, R.D. Hydrogels based on cellulose and chitin: Fabrication, properties, and applications. Green Chem. 2016, 18, 53-75. [CrossRef]

3. Wang, S.; Lu, A.; Zhang, L. Recent Advances in Regenerated Cellulose Materials. Prog. Polym. Sci. 2016, 53, 169-206. [CrossRef]

4. Mahmoud Nasef, M.; El-Hefian, E.A.; Saalah, S.; Yahaya, A.H. Preparation and properties of non-crosslinked and ionically crosslinked chitosan/agar blended hydrogel films. J. Chem. 2011, 8, S409-S419. [CrossRef]

5. Rodriguez, R.; Alvarez-Lorenzo, C.; Concheiro, A. Interactions of ibuprofen with cationic polysaccharides in aqueous dispersions and hydrogels: Rheological and diffusional implications. Eur. J. Pharm. Sci. 2003, 20, 429-438. [CrossRef] [PubMed]

6. Song, H.; Luo, Z.; Zhao, H.; Luo, S.; Wu, X.; Gao, J.; Wang, Z. High tensile strength and high ionic conductivity bionanocomposite ionogels prepared by gelation of cellulose/ionic liquid solutions with nano-silica. RSC Adv. 2013, 3, 11665-11675. [CrossRef]

7. Wang, T.; Turhan, M.; Gunasekaran, S. Selected properties of pH-sensitive, biodegradable chitosan-poly (vinyl alcohol) hydrogel. Polymer International. Polym. Int. 2004, 53, 911-918. [CrossRef]

8. Billiet, T.; Vandenhaute, M.; Schelfhout, J.; Van Vlierberghe, S.; Dubruel, P. A review of trends and limitations in hydrogel-rapid prototyping for tissue engineering. Biomaterials 2012, 33, 6020-6041. [CrossRef] [PubMed]

9. Sannino, A.; Pappada, S.; Madaghiele, M.; Maffezzoli, A.; Ambrosio, L.; Nicolais, L. Crosslinking of cellulose derivatives and hyaluronic acid with water-soluble carbodiimide. Polymer 2005, 46, 11206-11212. [CrossRef]

10. Acikara, Ö.B. Ion-Exchange Chromatography and Its Applications. In Column Chromatography; Martin, D.F., Martin, B.B., Eds.; Intech: London, UK, 2013. [CrossRef]

11. Luo, X.; Zhang, L. Creation of regenerated cellulose microspheres with diameter ranging from micron to millimeter for chromatography applications. J. Chromatogr. A 2010, 1217, 5922-5929. [CrossRef] [PubMed]

12. Du, K.F.; Yan, M.; Wang, Q.Y.; Song, H. Preparation and characterization of novel macroporous cellulose beads regenerated from ionic liquid for fast chromatography. J. Chromatogr. A 2010, 1217, 1298-1304. [CrossRef] [PubMed]

13. Fee, C.; Nawada, S.; Dimartino, S. 3D printed porous media columns with fine control of column packing morphology. J. Chromatogr. A 2014, 1333, 18-24. [CrossRef] [PubMed]

14. Lee, J.Y.; Tan, W.S.; An, J.; Chua, C.K.; Tang, C.Y.; Fane, A.G.; Chong, T.H. The potential to enhance membrane module design with 3D printing technology. J. Membr. Sci. 2016, 499, 480-490. [CrossRef]

15. Kosan, B.; Schwikal, K.; Meister, F. Solution states of cellulose in selected direct dissolution agents. Cellulose 2010, 17, 495-506. [CrossRef]

16. Kim, G.; Son, J.; Park, S.; Kim, W. Hybrid process for fabricating 3D hierarchical scaffolds combining rapid prototyping and electrospinning. Macromol. Rapid Commun. 2008, 29, 1577-1581. [CrossRef]

17. Kim, M.; Kim, G. 3D multi-layered fibrous cellulose structure using an electrohydrodynamic process for tissue engineering. J. Colloid Interf. Sci. 2015, 457, 180-187. [CrossRef] [PubMed]

18. Pattinson, S.W.; Hart, A.J. Additive Manufacturing of Cellulosic Materials with Robust Mechanics and Antimicrobial Functionality. Adv. Mater. Technol. 2017, 2. [CrossRef]

19. Li, L.; Zhu, Y.; Yang, J. 3D Bioprinting of Cellulose with Controlled Porous Structures from NMMO. Mater. Lett. 2018, 210, 136-138. [CrossRef]

20. Markstedt, K.; Escalante, A.; Toriz, G.; Gatenholm, P. Biomimetic Inks Based on Cellulose Nanofibrils and Cross-Linkable Xylans for 3D Printing. ACS Appl. Mater. Interf. 2017, 9, 40878-40886. [CrossRef] [PubMed]

21. Palaganas, N.B.; Mangadlao, J.D.; de Leon, A.C.C.; Palaganas, J.O.; Pangilinan, K.D.; Lee, Y.J.; Advincula, R.C. 3D Printing of Photocurable Cellulose Nanocrystal Composite for Fabrication of Complex Architectures via Stereolithography. ACS Appl. Mater. Interf. 2017, 9, 34314-34324. [CrossRef] [PubMed]

22. Tenhunen, T.-M.; Moslemian, O.; Kammiovirta, K.; Harlin, A.; Kääriäinen, P.; Österberg, M.; Tammelin, T.; Orelma, H. Surface tailoring and design-driven prototyping of fabrics with 3D-printing: An all-cellulose approach. Mater. Des. 2018, 140, 409-419. [CrossRef]

23. Chua, C.K.; Yeong, W.Y.; An, J. Special Issue: NextGen Materials for 3D Printing. Materials 2018, 11, 555. [CrossRef] [PubMed] 
24. Muzzarelli, R.A.; Boudrant, J.; Meyer, D.; Manno, N.; DeMarchis, M.; Paoletti, M.G. Current views on fungal chitin/chitosan, human chitinases, food preservation, glucans, pectins and inulin: A tribute to Henri Braconnot, precursor of the carbohydrate polymers science, on the chitin bicentennial. Carbohydr. Polym. 2012, 87, 995-1012. [CrossRef]

25. Geckil, H.; Xu, F.; Zhang, X.; Moon, S.; Demirci, U. Engineering hydrogels as extracellular matrix mimics. Nanomedicine. Future Med. 2010, 5, 469-484.

26. Li, R.; Wang, S.; Lu, A.; Zhang, L. Dissolution of cellulose from different sources in an $\mathrm{NaOH} /$ urea aqueous system at low temperature. Cellulose 2015, 22, 339-349. [CrossRef]

27. Qin, X.; Lu, A.; Zhang, L. Gelation behavior of cellulose in $\mathrm{NaOH} /$ urea aqueous system via cross-linking. Cellulose 2013, 20, 1669-1677. [CrossRef]

28. Cai, J.; Zhang, L. Unique gelation behavior of cellulose in $\mathrm{NaOH} /$ urea aqueous solution. Biomacromolecules 2006, 7, 183-189. [CrossRef] [PubMed]

29. Jin, H.; Zha, C.; Gu, L. Direct dissolution of cellulose in $\mathrm{NaOH} /$ thiourea/urea aqueous solution. Carbohydr. Res. 2007, 342, 851-858. [CrossRef] [PubMed]

30. Wang, Y.; Chen, L. Impacts of nanowhisker on formation kinetics and properties of all-cellulose composite gels. Carbohydr. Polym. 2011, 83, 1937-1946. [CrossRef]

31. Loth, F.; Philipp, B. The macroporous network of "bead cellulose" and its response to crosslinking with epichlorohydrin. Makromol. Chem. Macromol. Symp. 1989, 30, 273-287. [CrossRef]

32. Isobe, N.; Sekine, M.; Kimura, S.; Wada, M.; Kuga, S. Anomalous reinforcing effects in cellulose gel-based polymeric nanocomposites. Cellulose 2011, 18, 327-333. [CrossRef]

33. Abdelaal, O.A.; Darwish, S.M. Review of rapid prototyping techniques for tissue engineering scaffolds fabrication. In Characterization and Development of Biosystems and Biomaterials; Springer: Berlin, Germany, 2013; pp. 33-54.

34. Sun, J.; Zhou, W.; Huang, D.; Fuh, J.Y.; Hong, G.S. An overview of 3D printing technologies for food fabrication. Food Bioprocess Technol. 2015, 8, 1605-1615. [CrossRef]

35. Kwan, J.G. Design of Electronics for a High-Resolution, Multi-Material, and Modular 3D Printer. Ph.D. Thesis, Massachusetts Institute of Technology, Cambridge, MA, USA, 2013.

36. Brown, M.S.; Arnold, C.B. Fundamentals of laser-material interaction and application to multiscale surface modification. In Laser Precision Microfabrication; Springer: Berlin, Germany, 2010; pp. 91-120.

37. Qin, X.; Lu, A.; Cai, J.; Zhang, L. Stability of inclusion complex formed by cellulose in $\mathrm{NaOH} /$ urea aqueous solution at low temperature. Carbohydr. Polym. 2013, 92, 1315-1320. [CrossRef] [PubMed]

38. Huber, T.; Starling, K.; Cen, W.S.; Fee, C.; Dimartino, S. Effect of Urea Concentration on the Viscosity and Thermal Stability of Aqueous NaOH/Urea Cellulose Solutions. J. Polym. 2016, 2016. [CrossRef]

39. Han, D.; Yan, L. Preparation of all-cellulose composite by selective dissolving of cellulose surface in PEG/NaOH aqueous solution. Carbohydr. Polym. 2010, 79, 614-619. [CrossRef]

40. Ruan, D.; Lue, A.; Zhang, L. Gelation behaviors of cellulose solution dissolved in aqueous $\mathrm{NaOH} /$ thiourea at low temperature. Polymer 2008, 49, 1027-1036. [CrossRef]

41. Zhang, L.; Ruan, D.; Gao, S. Dissolution and regeneration of cellulose in $\mathrm{NaOH} /$ thiourea aqueous solution. J. Polym. Sci. Part B Polym. Phys. 2002, 40, 1521-1529. [CrossRef]

42. Hoepfner, S.; Ratke, L.; Milow, B. Synthesis and characterisation of nanofibrillar cellulose aerogels. Cellulose 2008, 15, 121-129. [CrossRef]

43. Yang, J.; Han, C.; Xu, F.; Sun, R. Simple approach to reinforce hydrogels with cellulose nanocrystals. Nanoscale 2014, 6, 5934-5943. [CrossRef] [PubMed]

44. Huber, T.; Müssig, J.; Curnow, O.; Pang, S.; Bickerton, S.; Staiger, M.P. A critical review of all-cellulose composites. J. Mater. Sci. 2012, 47, 1171-1186. [CrossRef]

45. Di Martino, A.; Sittinger, M.; Risbud, M.V. Chitosan: a versatile biopolymer for orthopaedic tissue-engineering. Biomaterials 2005, 26, 5983-5990. [CrossRef] [PubMed]

46. Kuo, C.K.; Ma, P.X. Ionically crosslinked alginate hydrogels as scaffolds for tissue engineering: Part 1. Structure, gelation rate and mechanical properties. Biomaterials 2001, 22, 511-521. [CrossRef]

47. Lohfeld, S.; Tyndyk, M.; Cahill, S.; Flaherty, N.; Barron, V.; McHugh, P. A method to fabricate small features on scaffolds for tissue engineering via selective laser sintering. J. Biomed. Sci. Eng. 2010, 3, 138. [CrossRef]

48. Wang, X.; Laoui, T.; Bonse, J.; Kruth, J.-P.; Lauwers, B.; Froyen, L. Direct selective laser sintering of hard metal powders: experimental study and simulation. Int. J. Adv. Manuf. Technol. 2002, 19, 351-357. [CrossRef] 
49. Li, V.C.-F.; Dunn, C.K.; Zhang, Z.; Deng, Y.; Qi, H.J. Direct Ink Write (DIW) 3D Printed Cellulose Nanocrystal Aerogel Structures. Sci. Rep. 2017, 7, 8018. [CrossRef] [PubMed]

50. Kimura, M.; Shinohara, Y.; Takizawa, J.; Ren, S.; Sagisaka, K.; Lin, Y.; Hattori, Y.; Hinestroza, J.P. Versatile Molding Process for Tough Cellulose Hydrogel Materials. Sci. Rep. 2015, 5, 16266. [CrossRef] [PubMed]

51. Sultan, S.; Mathew, A.P. 3D printed scaffolds with gradient porosity based on a cellulose nanocrystal hydrogel. Nanoscale 2018, 10, 4421-4431. [CrossRef] [PubMed]

52. Leppiniemi, J.; Lahtinen, P.; Paajanen, A.; Mahlberg, R.; Metsä-Kortelainen, S.; Pinomaa, T.; Pajari, H.; Vikholm-Lundin, I.; Pursula, P.; Hytönen, V.P. 3D-Printable Bioactivated Nanocellulose-Alginate Hydrogels. ACS Appl. Mater. Interfaces 2017, 9, 21959-21970. [CrossRef] [PubMed]

2018 by the authors. Licensee MDPI, Basel, Switzerland. This article is an open access article distributed under the terms and conditions of the Creative Commons Attribution (CC BY) license (http://creativecommons.org/licenses/by/4.0/). 